\title{
Pathogenesis of Acute Coronary Syndrome, from Plaque Formation to Plaque Rupture
}

\author{
Hamdan Righab ${ }^{1}$, Caussin Christophe ${ }^{1}$, Kadri Zena ${ }^{2}$ and Badaoui Georges ${ }^{2}$ \\ ${ }^{1}$ Marie Lannelongue Hospital, Cardiology Department, Plessis Robinson, \\ ${ }^{2}$ Hotel Dieu de France Hospital, Cardiology Department, Beirut, \\ 1France \\ ${ }^{2}$ Lebanon
}

\section{Introduction}

Cardiovascular diseases remain the leading cause of morality in the western world. The aim of this chapter is to understand the pathogenesis of acute coronary syndromes from atherosclerotic plaque formation, to plaque progression and vascular remodeling, to plaque destabilization, to ultimately plaque rupture or erosion and thrombus formation.

A cascade of interacting factors leads to plaque formation, progression, fraglisation, and rupture.

Features associated with plaque rupture are: large eccentric soft lipid core, thin fibrous cap, inflammation in the cap and adventitia, increased plaque neovascularity, and outward or positive vessel remodeling.

Vasospasm is a separate mechanism for developing ACS without plaque rupture or erosion will not be discussed in this chapter.

\section{Atherosclerosis}

Atherosclerosis is a chronic disease that can remain asymptomatic through decades. It is enhanced by modifiable and non modifiable risk factors and consists of intra intimal accumulation of intra cellular and extracellular oxidized LDL, macrophages, $\mathrm{T}$ cells, smooth muscle cells, proteoglycan, collagen, calcium, and necrotic debris. Low endothelial shear stress can contribute to atherosclerotic plaque formation, vulnerabilisation, and rupture. Intimal accumulation of oxidized LDL-C, called fatty streaks constitutes the earliest histopathologic stage of atherosclerosis.

Adhesion molecules expressed by endothelial cells mediate the rolling and adhesion of circulating leukocytes on the endothelial surface. Chemoattractant chemokines promote transmigration of leukocytes into the intima. Monocytes infiltrate beneath the endothelium, differentiate to macrophages, phagocytose the oxidized LDL-C and transform into foam cells. Foam cells produce cytokines, growth factors, reactive oxygen species and matrixdegrading enzymes, sustaining atherosclerosis progression. The intensity of oxidized LDL-C accumulation in the subendothelial space is a major stimulus for the ongoing inflammatory process. The accumulation of lipid-laden foam cells constitute the intermediate lesions or pathologic intimal thickening, which evolve through several stages of progression. 


\section{Arterial remodeling}

Arterial remodeling involves a cascade of structural and morphological changes of a vessel wall in response to various stimuli including changes in blood flow and pressure, and acute injury; all three are common findings in atherosclerotic plaques.

Two types of coronary arterial remodeling have been described:

- Negative remodeling: defined as local shrinkage, negative remodeling is more often seen in patients with stable angina and is associated with smaller plaque areas. It might be seen in arterial wall healing after injuries such as balloon injury, that could be mainly related to vascular wall contracture and consequent luminal narrowing. The biological events involved in this wound healing involve complex series of interacting growth factors, integrins and proteases.

- Positive or outward remodeling: defined by a compensatory increase in local vessel size in response to increasing plaque burden minimizing the degree of luminal stenosis.

Positive remodeling characterizes unstable vulnerable plaques.

There are studies demonstrating that plaque rupture occurs in insignificant, mildly occlusive plaques, this could be explained by positive remodeling: the increase in total arterial area that accompanies plaque accumulation. Large positive remodeled plaques while paradoxically protecting against luminal narrowing, are more susceptible to mechanical forces that lead to plaque rupture and an unstable clinical presentation.

The pathogenesis of arterial remodeling is not fully understood and remains debated. Many hypotheses have been advanced.

Arterial wall neovascularisation of atherosclerotic plaques seems to have a potential role in modulating lesion formation and structural changes of the arterial wall, by nourishing the growing plaque. Various angiogenic growth factors and receptors are implicated in coronary wall angiogenesis such as VEGF/VPF, estrogen, interleukin 8, bFGF, and aFGF; the role of TNF- $\alpha$ and TGF- $\beta$ remains controversial.

Angiotensine II via AT1 receptors is another trigger of plaque neovascularisation and remodeling.

Activation of NADPH oxidase by various triggers such as Angiotensine II and mechanical stretch promotes ROS production and ROS-mediated pathways leading to vascular remodeling. In addition Low ESS leads to inflammation of the wall beneath the plaque and shift of the extracellular matrix balance toward degradation. Within such an environment the internal elastic lamina undergoes severe fragmentation, and the atherosclerotic process extends into the media degrading the collagen and elastin fibers, thereby promoting arterial expansion and outward remodeling.

Human studies using intravascular ultrasound confirmed that outward or positive remodeling is more common at culprit lesion sites in patients with unstable angina, whereas inward or negative remodeling is more common in patients with stable angina.

\begin{tabular}{|l|}
\hline Pathogenesis of positive arterial remodeling \\
\hline Arterial wall neovascularisation \\
\hline Angiotensine II \\
\hline ROS \\
\hline Low ESS \\
\hline
\end{tabular}

Table 1. This table summarizes factors contributing to positive plaque remodeling that is associated with unstable plaque. 


\section{Plaque destabilisation}

Typically a vulnerable plaque is described as having a thin fibrous cap and a rich superficial lipid core. Weakening of the fibrous cap is due mainly to accelerated degradation of collagen and other matrix components.

Many factors contribute to plaque vulnerabilisation:

\subsection{Inflammation}

Inflammation cells such as activated monocytes and macrophages and, to a lesser degree, $\mathrm{T}$ cells play a crucial role in destabilizing the fibrous cap tissue and, therefore, enhance the risk of plaque rupture.

Adhesion molecules such as VCAM-1 as well as chemokines such as MCP-1 recruite inflammatory cells into the atherosclerotic plaques. Inflammatory cells are activated in the vessel wall by oxidized lipids and cytokines such as M-CSF.

Adventitial neovasculature also enhances inflammatory cells entry and recruitement inside the atherosclerotic lesion.

Many mediators secreted by plaque macrophages could be involved in fibrous cap weakening including:

- Interleukin (IL)-18: also called interferon gamma-inducing factor, is a proinflammatory cytokine secreted by plaque macrophages. Increased serum IL-18 may be an independent predictor of cardiovascular mortality.

- Matrix Metalloproteinases (MMP): mainly MMP-2 (Gelatinse A), MMP-9 (Gelatinase B), and MMP-8 (Collagenase), released from activated macrophage foam cells, directly mediate matrix degradation of the plaque fibrous cap. Oxidized LDL containing arachidonic and linoleic acid upregulates the expression of metalloproteinase, while HDL reverses this effect.

- Tissue factor: expressed by macrophages is the main initiator of thrombogenesis. Inflammation usually concerns the entire coronary circulation not only the culprit lesion. This fact explains why patients with acute coronary syndrome may have multiple vulnerable plaques.

\begin{tabular}{|l|}
\hline Mechanisms of Angiotensine II mediated plaque weakening \\
\hline Upregulation of IL6 gene \\
\hline Upregulation of MMP genes \\
\hline Activation of mitogen-activated protein kinase cascades \\
\hline Activation of tyrosine kinases \\
\hline Stimulation of neovascularisation \\
\hline
\end{tabular}

Table 2. This table summarizes the leading mechanisms of Angiotensine II mediated atherosclerotic plaque weakening 


\subsection{Renin-angiotensin system}

There is evidence of angiotensin converting enzyme (ACE), angiotensine II, and AT1 receptors within the plaque. An increased activity of ACE was found within culprits lesions in the setting of acute coronary syndromes, probably related to a local secretion. Angiotensine II increases the likelihood of plaque progression and rupture via AT1 receptors by regulating the gene expression of various bioactive substances mainly interleukine 6 (IL6), metalloproteinases, and other growth factors and cytokines. Angiotensine II also activates multiple intracellular signaling cascades (mitogen-activated protein kinase cascades, tyrosine kinases, and various transcription factors) in coronary endothelial and smooth muscle cells.

In addition Angiotensine II enhances plaque neovascularisation.

\subsection{Hemodynamical factors mainly shear stress}

\subsubsection{Definitions}

- Endothelial shear stress (ESS): tangential force derived by the friction of the flowing blood on the endothelial surface. It is the product of the shear rateat the wall and the blood viscosity.

- Shear rate: The spatial gradient of blood velocity from areas at the arterial wall toward areas at the center of the lumen $(\mathrm{dv} / \mathrm{dy}$, where $\mathrm{dv}$ is change in flow velocity and dy is change in radial distance from the wall).

Physiologically, the shear rate decreases at the center of the lumen and gradually increases toward the wall.

- Blood viscosity: A principal property of blood related to its internal friction that causes blood to resist flow. Hematocrit is the major determinant of blood viscosity.

Although the entire vasculature is exposed to the atherogenic effects of the systemic risk factors such as hyperlipidemia, cigarette smoking, hypertension, diabetes mellitus, and genetic predisposition, atherosclerotic lesions form at specific regions of the arterial tree, such as in the vicinity of branch points, the outer wall of bifurcations, and the inner wall of curvatures, where disturbed flow occurs and ESS is low.

Low ESS induces endothelial dysfunction by reducing the bioavailability of nitric oxid via a decrease in eNOS messenger ribonucleic acid and protein expression, thereby exposing the endothelium to the atherogenic effect of local and systemic risk factors. Nitric oxide is a key component of normal vascular tone, characterized by strong anti-inflammatory, antiapoptotic, anti-mitogenic, and anti-thrombotic properties. In addition, low ESS downregulates prostacyclin, another endothelial vasodilatory substance and upregulates endothelin-1, a potent vasoconstrictive and mitogenic molecule.

Low ESS also promotes subendothelial deposition and accumulation of LDL-C by increasing mitotic and apoptotic activity of endothelial cells and inducing conformational changes of endothelial cells from fusiform to polygonal shape, widening thereby the junctions between endothelial cells.

Gene expression as well as post-transcriptional activity of the major oxidative enzymes at endothelial cell membranes are enhanced by low ESS, leading to the production of reactive oxygen species within the intima.

In addition gene expression of several adhesion molecules, chemoattractant chemokines and proinflammatory cytokines are upregulated by low ESS. 


\begin{tabular}{|l|}
\hline Mechanisms of low ESS mediated plaque weakening \\
\hline Endothelial dysfunction: \\
- Decreases eNOS \\
- Downregulates Prostacycline synthesis \\
- Upregulates Endotheline-1 synthesis \\
\hline LDL-C sub-intimal uptake and accumulation \\
\hline Promotes inflammation \\
\hline Promotes oxidative stress \\
\hline
\end{tabular}

Table 3. This table summarizes the contribution of low ESS to plaque weakening.

\subsection{Strenuous exercise}

Strenuous exercise especially among those who exercise infrequently and have multiple cardiac risk factors, is associated with increased temporary risk of plaque rupture and myocardial infarction via increase wall stress due to rapid increase in heart rate and blood pressure, coronary vasospasm, increased flexing of epicardial coronary arteries, deepening of existing plaque fissures, and catecholamine induced platelet aggregation.

\subsection{In vivo detection of vulnerable plaque with optical coherence tomography}

Optical coherence tomography (OCT) is recently developed imaging modality, using infra

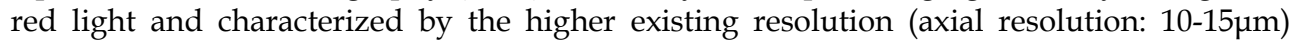
allowing a microscopical description of the atherosclerotic plaque in vivo within the coronary arteries. OCT is validated for the detection of vulnerable plaque wich is typically characterized by:

- $\quad$ Thin fibrous cap $<65 \mu \mathrm{m}$

- $\quad$ Rich lipid core: when lipid is present within two or more quadrants of the plaque.

- Microchannels in case of plaque neovascularisation.

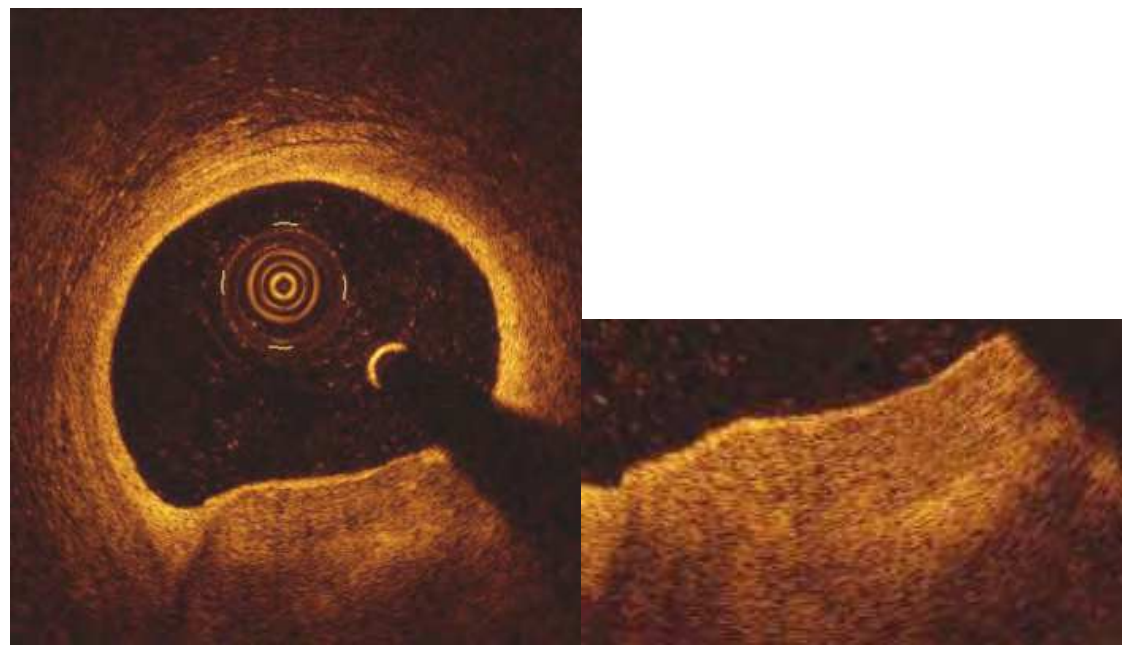

Fig. 1. Fibrous cap assessment with OCT: fibrous cap is a signal rich layer separating the lumen from the signal poor underlying lipid core. Fibrous cap is measured at its thinest segment. 


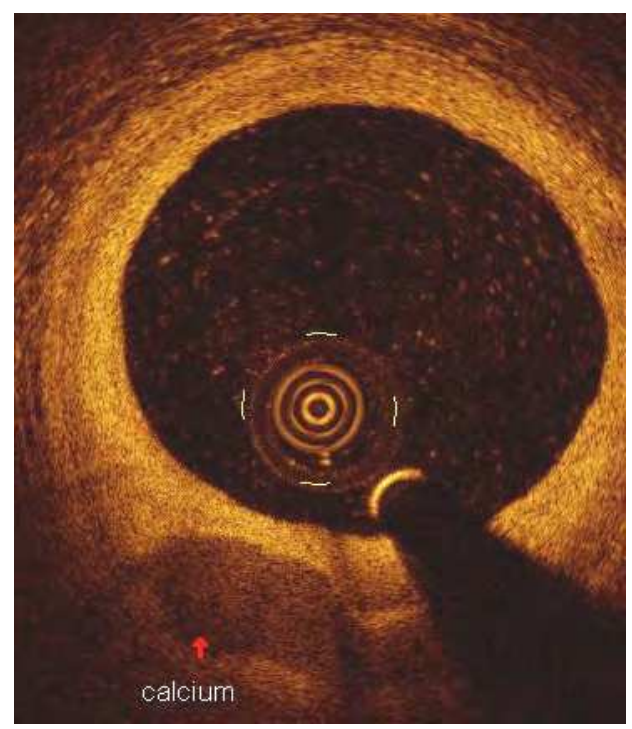

Fig. 2. OCT showing a thick fibrous cap, calcified plaque. Calcium is seen as a homogeneous signal poor region with sharply demarcated edges.

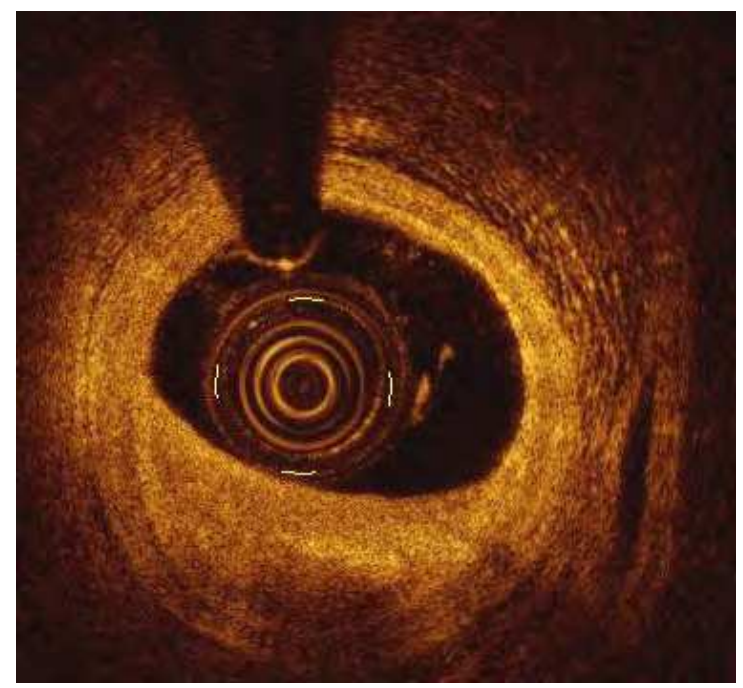

Fig. 3. OCT showing a lipid rich plaque. Lipid is seen as a heterogeneous signal poor region with irregular edges. 

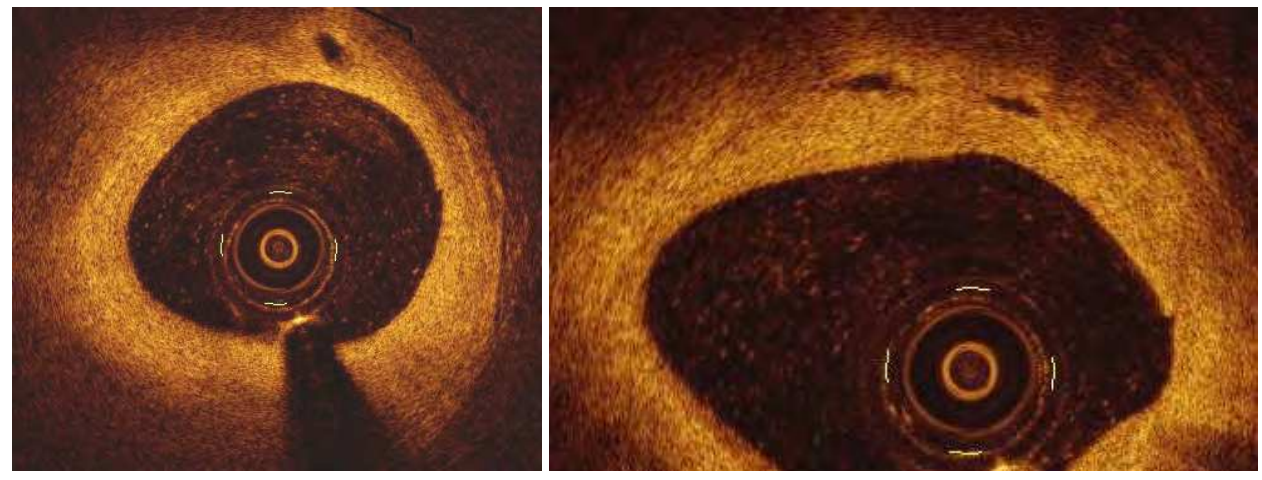

Fig. 4. Adventicial and subintimal increazed neovascularization characterizes unstable plaque and can be detected in vivo with OCT. Neovessels or microchannels are seen as nosignal tubulo-luminal structure without a connection to the vessel lumen and recognized on $\geq 3$ consecutive cross sectional OCT images.

\section{Plaque rupture}

As previously explained the fibrous cap rupture results from an imbalance between synthesis and breakdown of extracellular matrix collagen and other matrix components leading to thinning of the cap, predisposing the cap to spontaneous rupture or rupture in response to a variety of triggers. Plaque rupture primarily occurs in yellowish plaques with an increased lipid core and thin fibrous cap. Rupture of the thin fibrous cap exposes blood flow to the lipid core. The lipid core is believed to be highly thrombogenic when exposed to circulating blood. The enhanced thrombogenicity of the lipid core has been attributed to the high levels of functionally active tissue factor most likely derived from the death of macrophages inside the plaque. In addition to tissue factor, oxidized lipids in the lipid core may also directly stimulate platelet aggregation.

The thrombus is usually occlusive in STEMI and nonocclusive in NSTEMI. Episodes of plaque disruption and thrombosis may be subclinical and do not always result in acute coronary syndrome. Healing process may play an integral role in the progression of atherosclerosis, having the potential to cause sudden plaque growth. 


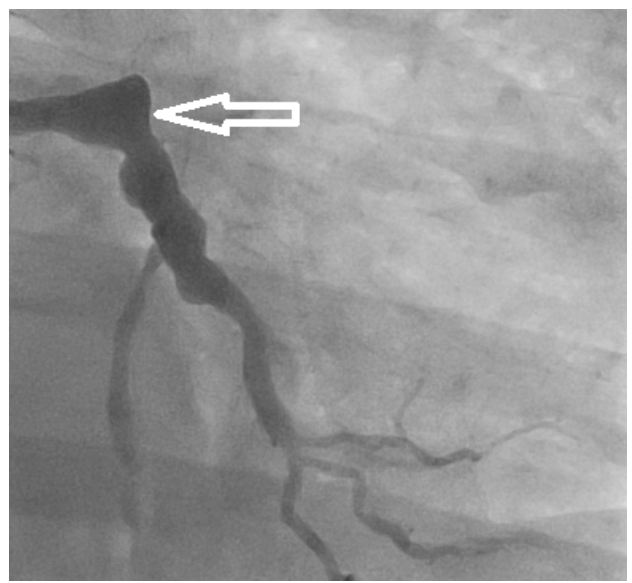

A

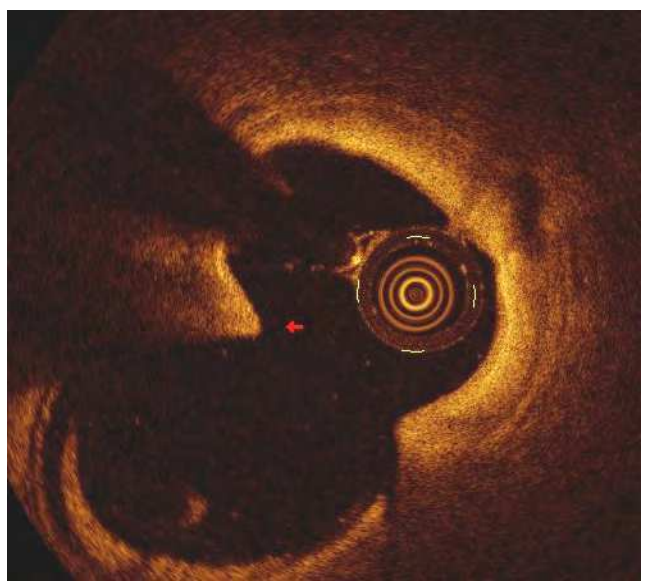

B

Fig. 5. (A)- Coronary angiogram showing ostial occlusion (TIMI 0 flow) of the left ascending artery responsible of acute STEMI; (B)- OCT performed in the same patient after thromboaspiration and restauration of a TIMI 3 flow, shows the site of plaque rupture, defined by a discontinuation of the fibrous cap and cavity formation within the plaque.
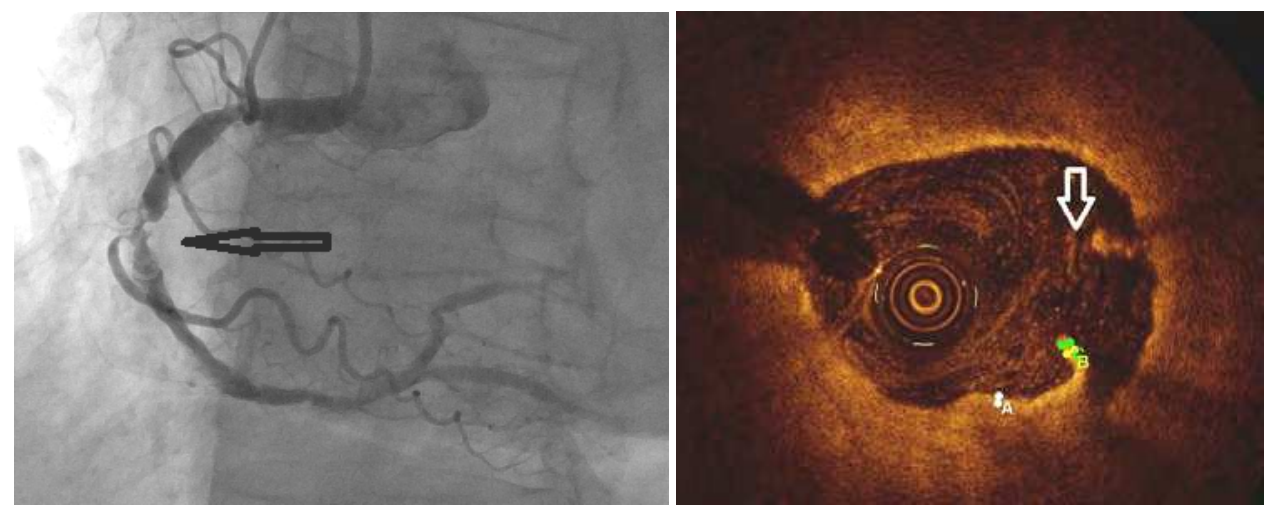

Fig. 6. Rupture site detected with OCT (right) in the setting of NSTEMI. The coronary angiogram (left) shows a subocclusion of the segment 2 of the right coronary artery. 


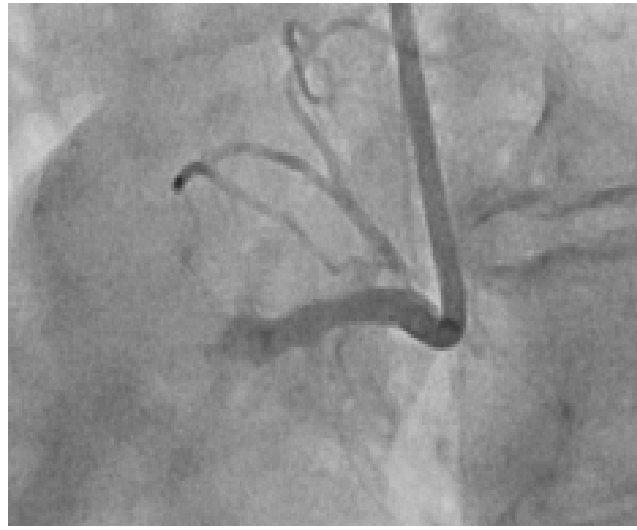

A

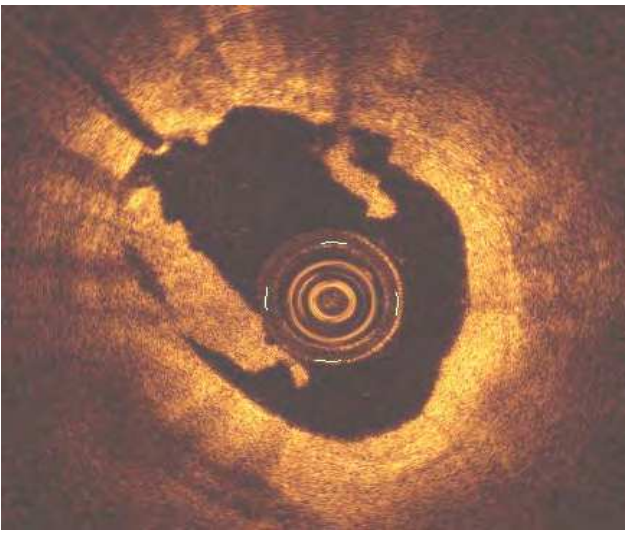

B

Fig. 7. (A)- Coronary angiogram showing occlusion of the segment 1 of right coronary artery in a patient presenting with STEMI; (B)- OCT performed after thrombo-aspiration showed residual white thrombus seen as a hypersignal protrusion within the lumen.
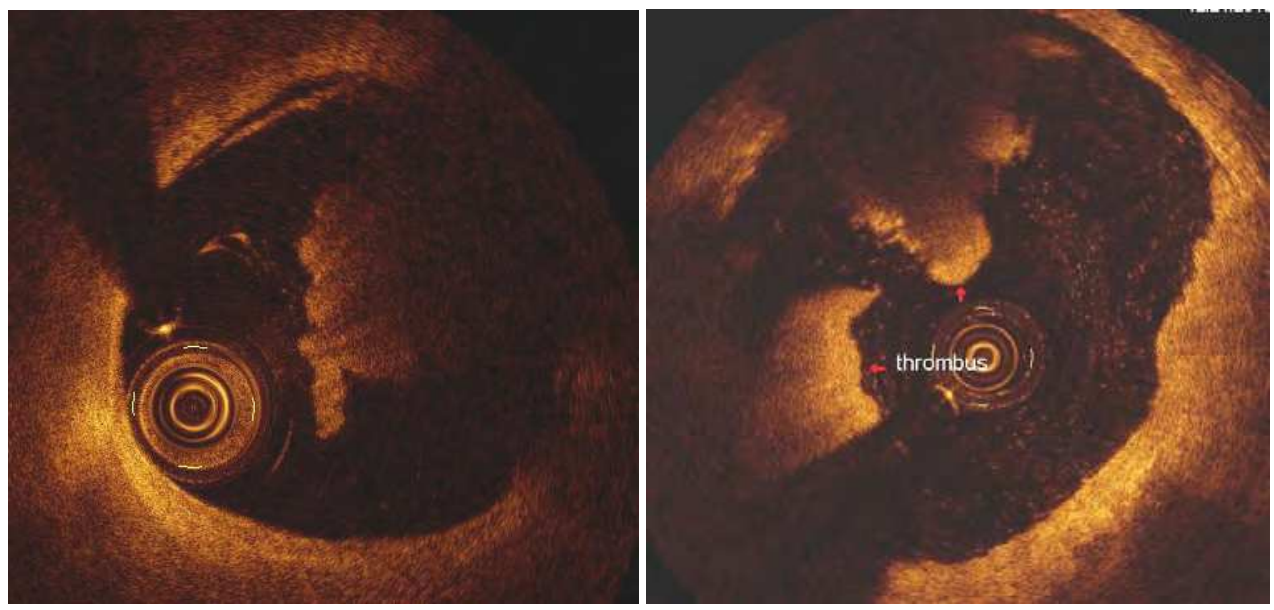

Fig. 8. Red thrombus in the setting of ACS is seen with OCT as hypersignal protusion within the lumen, however, unlike white thrombus, red thrombus is characterised by a signal attenuation and posterior signal free shadowing due to the backscatering properties of the red blood cells wich are highly present in red thrombus. 


\section{Plaque erosion}

Plaque erosion usually occurs in younger patients, women and smokers.

Culprit lesion do not have a large lipid core but instead have a proteoglycan-rich matrix, a deep lipid core, the prevalence of inflammation is lower with less macrophages and $\mathrm{T}$ cells and more smooth muscle cells compared to culprit lesions in plaque ruptures. Plaque erosion is defined as acute thrombus in direct contact with the intimal plaque without rupture of a lipid pool. The plaque luminal surface is irregular and eroded.

Thrombus resulting from plaque erosion has been reported to be $20 \%$ to $40 \%$ of all coronary thrombi. The precise mechanisms of thrombosis in this entity are not known.

Thrombosis in such cases might be triggered by an enhanced systemic thrombogenic state such as enhanced platelet aggregability, increased circulating tissue factor levels, and depressed fibrinolytic state. In addition activated circulating leucocytes may transfer active tissue factor by shedding microparticles and transferring them onto adherent platelets. Virmani et al have also identified yet another pathological variant where a calcified nodule within the plaque erodes through the surface of the plaque leading to thrombosis.

\section{Abbreaviations}

\begin{tabular}{ll}
\hline ACS & Acute coronary syndrome \\
LDL-C & Low density lipoprotein cholesterol \\
ESS & Endothelial shear stress \\
VEGF & Vascular endothelial growth factor \\
VPF & Vascular permeability factor \\
FGF & Fibroblast growth factor \\
TNF & Tumor necrosis factor \\
TGF & Transforming growth factor \\
AT1 & Angiotensine type 1 \\
IL & Interleukine \\
MMP & Matrix metalloproteinase \\
NADPH & Nicotinamide Adenosine Dinucleotide Phosphate \\
VCAM & Vascular cellular adhesion molecule \\
ROS & Reactive oxygen species \\
MCP & Monocyte Chemotactic Protein \\
CSF & Colony stimulating factor \\
ACE & Angiotensine converting enzyme \\
HDL & High density lipoprotein \\
eNOS & Endothelial nitric oxide synthase \\
OCT & Optical coherence tomography \\
TIMI & Thrombolysis In Myocardial Infarction \\
STEMI & ST elevation myocardial infarction \\
NSTEMI & Non ST elevation myocardial infarction \\
\hline
\end{tabular}




\section{References}

[1] Molecular bases of the acute coronary syndrome. Libby, P. Circulation 1995; 91:2844.

[2] Evidence for increased collagenolysis by interstitial collagenases- 1 and -3 in vulnerable human atheromatous plaques. Sukhova GK, Schonbeck U, Rabkin E, et al. Circulation 1999; 99:2503.

[3] Site of intimal rupture or erosion of thrombosed coronary atherosclerotic plaques is characterized by an inflammatory process irrespective of the dominant plaque morphology. Van der Wal AC, Becker AE, Van der Loos CM, Das PK. Circulation 1994; 89:36.

[4] Focal and multi-focal plaque macrophage distributions in patients with acute and stable presentations of coronary artery disease. MacNeill BD, Jang IK, Bouma BE, et al.. J Am Coll Cardiol 2004; 44:972.

[5] Increased expression of membrane type 3-matrix metalloproteinase in human atherosclerotic plaque: role of activated macrophages and inflammatory cytokines. Uzui H, Harpf A, Liu M, et al. Circulation 2002; 106:3024.

[6] Oxidized low density lipoprotein regulates matrix metalloproteinase-9 and its tissue inhibitor in human monocyte-derived macrophages. Xu X-P, Meisel SR, Ong JM, et al. Circulation 1999; 99:993.

[7] Expression of angiotensin II and interleukin 6 in human coronary atherosclerotic plaques: potential implications for inflammation and plaque instability. Schieffer B, Schieffer E, Hilfiker-Kleiner D, et al. Circulation 2000; 101:1372.

[8] Distribution of inflammatory cells in atherosclerotic plaques relates to the direction of flow. Dirksen MT, van der Wal AC, van den Berg FM, et al.Circulation 1998; 98:2000.

[9] Association between myocardial infarction and the mast cells in the adventitia of the infarct-related coronary artery. Kaartinen M, Penttila A, et al. Circulation 1999; 99:361.

[10] Prevalence of total coronary occlusion during the early hours of transmural myocardial infarction. DeWood MA, Spores J, Notske R, et al. N Engl J Med 1980; 303:897.

[11] Coronary arteriographic findings in acute transmural myocardial infarction. DeWood MA, Spores J, Hensley GR, et al. Circulation 1983; 68:I39.

[12] The non-Q wave myocardial infarction revisited: 10 years later. Liebson PR, KleinLW et al. Prog Cardiovasc Dis 1997; 39:399.

[13] Elevations in troponin $\mathrm{T}$ and I are associated with abnormal tissue level perfusion: a TACTICS-TIMI 18 substudy. Treat Angina with Aggrastat and Determine Cost of Therapy with an Invasive or Conservative Strategy-Thrombolysis in Myocardial Infarction. Wong GC, Morrow DA, Murphy S, et al. Circulation 2002; 106:202.

[14] A Prospective Natural-History Study of Coronary Atherosclerosis. Stone G, Maehara A, Lansky A, de Bruyne B, Cristea E, Mintz G, Mehran R, McPherson J, Farhat N, Marso S, Parise H, Templin B, White R, Zhang Z, Serruys P, for the PROSPECT Investigators. N Engl J Med 2011;364:226-35.

[15] Coronary plaque erosion without rupture into a lipid core a frequent cause of coronary thrombosis in sudden coronary death. Farb A, Burke AP, Tang AL, Liang TY, Mannan P, Smialek J, Virmani R. Circulation. 1996 Apr 1;93(7):1354-63.

[16] Exercise and acute cardiovascular events placing the risks into perspective: a scientific statement from the American Heart Association Council on Nutrition, Physical 
Activity, and Metabolism and the Council on Clinical Cardiology.Thompson PD, Franklin BA, Balady GJ, Blair SN, Corrado D, Estes NA 3rd, Fulton JE, Gordon NF, Haskell WL, Link MS, Maron BJ, Mittleman MA, Pelliccia A, Wenger NK, Willich SN, Costa F; American Heart Association Council on Nutrition, Physical Activity, and Metabolism; American Heart Association Council on Clinical Cardiology; American College of Sports Medicine.Circulation. 2007 May 1;115(17):2358-68.

[17] Shed membrane microparticles with procoagulant potential in human atherosclerotic plaques: a role for apoptosis in plaque thrombogenicity. Mallat Z, Hugel B, Ohan J, Lesèche G, Freyssinet JM, Tedgui A. Circulation. 1999 Jan 26;99(3):348-53

[18] Pathophysiology of Coronary Thrombosis: Role of Plaque Rupture and Plaque Erosion. Shah P K, Progress in Cardiovascular Diseases, Vol. 44, No. 5, 2002: pp 357-368.

[19] Role of Endothelial Shear Stress in the Natural History of Coronary Atherosclerosis and Vascular Remodeling Molecular, Cellular, and Vascular Behavior. Chatzizisis Y S, Coskun A U, Jonas M, Edelman E R, Feldman C L, Stone P H, JACC Vol. 49, No. 25, 2007;June 26, 2007:2379-93.

[20] Forum Review Article Cyclic Stretch, Reactive Oxygen Species,and Vascular Remodeling. Birukov K G. antioxidant and signaling;Volume 11, Number 7, 2009.

[21] Relationship Between Coronary Artery Remodeling and Plaque Composition in Culprit Lesions An Intravascular Ultrasound Radiofrequency Analysis. Higashikuni Y,Tanabe K, Yamamoto H, Aoki J, Nakazawa G, MD; Onuma Y, Otsuki S, Yagishita A, Yachi S,Nakajima H, Hara K. Circ J 2007; 71: 654 -660.

[22] Morphological Predictors of Arterial Remodeling in Coronary Atherosclerosis. Burke A, Kolodgie F D, Farb A,Weber D, Virmani R. Circulation 2002;105;297-303.

[23] Proteolysis of the Pericellular Matrix: A Novel Element Determining Cell Survival and Death in the Pathogenesis of Plaque Erosion and Rupture. Lindstedt K, Leskinen M, Kovanen P. Arterioscler Thromb Vasc Biol 2004; 24; 1350-1358.

[24] Differential Accumulation of Proteoglycans and Hyaluronan in Culprit Lesions: Insights Into Plaque Erosion. Kolodgie F, Burke A, Farb A, Weber D, Kutys R,Wight T, Virmani R. Arterioscler Thromb Vasc Biol 2002;22;1642-1648

[25] Clinical Classification and Plaque Morphology Determined by Optical Coherence Tomography in Unstable Angina Pectoris. Mizukoshi M, Imanishi T, Tanaka A, Kubo T, Liu Y, Takarada S, Kitabata H, Tanimoto T, Komukai K, Ishibashi K, Akasaka T. Am J Cardiol 2010;106:323-328.

[26] Diagnostic accuracy of optical coherence tomography and integrated backscatter intravascular ultrasound images for tissue characterization of human coronary plaques. Kawasaki M, Bouma BE, Bressner J, Houser SL, Nadkarni SK, MacNeill BD, Jang IK, Fujiwara H, Tearney GJ. J Am Coll Cardiol. 2006 Jul 4; 48(1):81-8.

[27] Assessment of Coronary Arterial Thrombus by Optical Coherence Tomography. Kume T, Akasaka T, Kawamoto T, Ogasawara Y, Watanabe N, Toyota E, Neishi Y, Sukmawan R, Sadahira Y, Yoshida K; Am J Cardiol, 2006;97:1713-1717.

[28] Relation of microchannel structure identified by optical coherence tomography to plaque vulnerability in patients with coronary artery disease. Kitabata $\mathrm{H}$, Tanaka A, Kubo T, Takarada S, Kashiwagi M, Tsujioka H, Ikejima H, Kuroi A, Kataiwa H, Ishibashi K, Komukai K, Tanimoto T, Ino Y, Hirata K, Nakamura N, Mizukoshi M, Imanishi T, Akasaka T. Am J Cardiol. 2010 Jun 15;105(12):1673-8. 


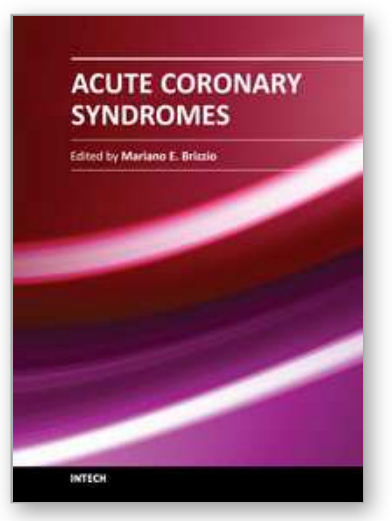

\author{
Acute Coronary Syndromes \\ Edited by Dr. Mariano Brizzio
}

ISBN 978-953-307-827-4

Hard cover, 214 pages

Publisher InTech

Published online 24, February, 2012

Published in print edition February, 2012

This book has been written with the intention of providing an up-to-the minute review of acute coronary syndromes. Atherosclerotic coronary disease is still a leading cause of death within developed countries and not surprisingly, is significantly rising in others. Over the past decade the treatment of these syndromes has changed dramatically. The introduction of novel therapies has impacted the outcomes and surviving rates in such a way that the medical community need to be up to date almost on a "daily bases". It is hoped that this book will provide a timely update on acute coronary syndromes and prove to be an invaluable resource for practitioners seeking new and innovative ways to deliver the best possible care to their patients.

\title{
How to reference
}

In order to correctly reference this scholarly work, feel free to copy and paste the following:

Hamdan Righab, Caussin Christophe, Kadri Zena and Badaoui Georges (2012). Pathogenesis of Acute Coronary Syndrome, from Plaque Formation to Plaque Rupture, Acute Coronary Syndromes, Dr. Mariano Brizzio (Ed.), ISBN: 978-953-307-827-4, InTech, Available from: http://www.intechopen.com/books/acutecoronary-syndromes/pathogenesis-of-acute-coronary-syndrome-from-plaque-formation-to-plaque-rupture

\section{INTECH}

open science | open minds

\section{InTech Europe}

University Campus STeP Ri

Slavka Krautzeka 83/A

51000 Rijeka, Croatia

Phone: +385 (51) 770447

Fax: +385 (51) 686166

www.intechopen.com

\section{InTech China}

Unit 405, Office Block, Hotel Equatorial Shanghai

No.65, Yan An Road (West), Shanghai, 200040, China

中国上海市延安西路65号上海国际贵都大饭店办公楼 405 单元

Phone: +86-21-62489820

Fax: $+86-21-62489821$ 
(C) 2012 The Author(s). Licensee IntechOpen. This is an open access article distributed under the terms of the Creative Commons Attribution 3.0 License, which permits unrestricted use, distribution, and reproduction in any medium, provided the original work is properly cited. 